DE DE GRUYTER OPEN
Research Article

(C) 2017 Nik Hanan Mustapha and Nik Farhan Mustapha. This is an open access article licensed under the Creative Commons Attribution-NonCommercial-NoDerivs License (http://creativecommons.org/licenses/by-nc-nd/3.0/).

\title{
Grammar Efficacy and Grammar Performance: An Exploratory Study on Arabic Learners
}

\author{
Nik Hanan Mustapha \\ Kulliyyah of Islamic Revealed Knowledge and Human Sciences, \\ International Islamic University Malaysia \\ Corresponding Author \\ Nik Farhan Mustapha \\ Faculty of Modern Languages and Communication, \\ Universiti Putra Malaysia
}

Doi: $10.1515 / \mathrm{mjss}-2017-0011$

\section{Abstract}

Previous research has clearly documented that self-efficacy in language learning positively affects students' performance in acquiring language skills. While much research has studied grammar efficacy indirectly as part of writing efficacy, none of these focuses on Arabic language learning. Considering the impact of self-efficacy on language learning, as well as the important role of grammar in Arabic learning, this study examines the relationship between grammar efficacy and grammar performance among students learning Arabic as a foreign language in Malaysian public universities. Specifically, it intends to determine the relationship between grammar efficacy and grammar performance among Arabic learners on three aspects: Correction of grammar errors, vocalization of words, and construction of sentences. Using a newly-developed questionnaire, 140 students majoring in Arabic language from a public university in Malaysia participated in the study. The questionnaire covers three important aspects in Arabic grammar learning: Correction of grammar errors, vocalization of words, and construction of sentences. This study showed a moderate correlation between grammar efficacy and grammar performance. Efficacy of sentence construction appeared to correlate the highest among the three aspects. Teachers' awareness on the importance of heightening students perceived confidence in accomplishing grammar tasks will eventually promote better learning among students.

Keywords: Achievement, Arabic, grammar efficacy, grammar performance, morphology, syntax

\section{Introduction}

Individuals differ in their judgments of any task they will perform. Their perceived confidence in task execution is dependable upon the abilities and skills they have possessed. Until the execution is completed, certainty about the success or failure of the task being performed could not be established. However, research in the field of self-efficacy has proved that perceived judgment is largely associated with the outcomes. Individuals who initially assessed themselves as capable of doing the assigned task will strive to overcome any obstacles, thus, producing better results.

Putting this self-concept in the aspect of language learning, much could be done to properly utilize it. Enhancing self-efficacy in learning any difficult linguistic components can pave ways for improving students' performance in learning as well as their language application. For learning Arabic, grammar has long been regarded as the core of learning Arabic language, whereas learners often complain on the difficulty of mastering it. The current scenario is not really surprising 
as traditional scholars have long called for the simplification of Arabic grammar.

Taking into consideration both the importance of pre-judgment in learning and the perceived difficulty in studying grammar for Arabic learners, this study will examine the level of grammar efficacy among Arabic learners and the association between grammar efficacy in different aspects of grammar application and students performance. It is hoped that the inclusion of self-efficacy in learning grammar will pave ways for both students and teachers for better application of grammar knowledge.

\section{Review of Literature}

In 1986, Albert Bandura developed the Social Cognitive Theory of which self-efficacy is a component. Within the realm of language learning, self-efficacy relates to the learner's cognitive process in assessing his/her language capabilities and arranging them while attending to specific language tasks. Consequently, self-efficacy allows the learner to appropriately choose the task, make the effort, persevere and in the process, achieve the intended results in learning a language (Bandura, 1986).

Pajares (1996) and Zimmerman (1996) maintain that general assessment of self-efficacy can only contribute to a general sense of confidence. The abilities of the participants who complete the questionnaires on general efficacy are only evaluated without them actually comprehending the specificity of the questions. Across all language skills - speaking, listening, reading and writing language learning for different individuals may vary; this covers tasks like speaking in public, listening to news broadcasts, reading academic texts and writing letters. Self-efficacy cannot be generalised across all skills or all language tasks because results of general assessments on them do not accurately measure the learner's self-efficacy. Hence, evaluation of self-efficacy must be domain specific or task specific to gain more accurate results.

Current research suggests that self-efficacy in language learning has positively affected learners' achievement in acquiring language skills (Linnenbrink \& Pintrich, 2003; Mills et al., 2006; Mills et al., 2007; Pajares, 2003; Pajares \& Johnson, 1994; Schunk, 2003; Schunk \& Zimmerman, 2007). However, many of these studies have concentrated on looking at grammar efficacy indirectly as part of writing efficacy (Collins \& Bissell, 2002; Pajares \& Johnson, 1994; Shell et al., 1995). Only one study by Collins and Bissell (2004) has mainly centred on grammar efficacy where they examined self-efficacy among community college students in their learning of grammar in an introductory media writing course. The findings indicate a weak yet positive correlation $(r=.30$, $\mathrm{p}<.05$ ) between grammar self-efficacy and grammar performance on a pre-test grammar quiz. No significant correlation is found on the post-test quiz. Thus, this study proposes that if language learners make more effort to learn the language by doing extra practise, it would benefit them in that it would enhance their self-efficacy.

Until recently, there has been very little empirical evidence on self-efficacy in Arabic language learning, what more on the grammar itself. In Malaysian context, Ghazali et al. (2011) examined self-efficacy among university students learning Arabic using The Motivated Strategies for Learning Questionnaire (MSLQ). However, their main focus was only on the speaking skill. In a broader scope, Mohamad Azrien and Shukeri (2011) explored the relationship between language strategies and self-efficacy on four aspects: reading, listening, speaking, and vocabulary. Thus, it is apparent that both studies have not paid attention to grammar whereas it is regarded as the nucleus in learning Arabic. Realizing the importance learning grammar in the context of Arabic learning in Malaysia, as well as the need for an accurate measurement for efficacy in Arabic language learning, Nik Hanan et al. (2013) proposed a specific instrument called Arabic Language Efficacy Questionnaire (ALEQ). It caters for three major components which are reading, writing and grammar. The study revealed that Arabic learners are highly efficacious in grammar, followed by writing, and reading. Correlation analysis indicated significant positive relationships between these components and the overall performance. However, this study lacks comprehensiveness on the part of grammar; it focuses merely on one aspect of Arabic grammar, which is the vocalization of words. Hence, there is a need for a broader assessment on grammar efficacy, especially on the application of grammar knowledge. 
Thus, this study will examine the relationship between grammar efficacy and grammar performance. Grammar efficacy in this research refers to learners' perceived judgment in the application of their grammar knowledge. Since it is very crucial for self-efficacy to be task-based for an accurate measurement (Pajares, 1996), this study will focus on three major aspects in the learning of Arabic grammar: correction of grammar errors, vocalization of words, and construction of sentences. Those three aspects cover both syntax and morphology. Basically, this research will test the following hypotheses:

1. Students of Arabic are highly efficacious in their application of grammar knowledge.

2. Grammar efficacy on error correction, words vocalization and sentence construction positively correlate with grammar performance.

\section{Methodology}

\subsection{Participants}

In this study, 140 participants were randomly selected from students majoring in Arabic language from a public university in Malaysia. According to Krejcie and Morgan (1970), the number is considered appropriate so as to generalize results back to the population $(\mathrm{N}=210)$. The majority of them $(71 \%)$ were female $(n=100)$ while the remaining $(29 \%)$ were male $(n=40)$. More than half $(59 \%)$ were in their third year $(n=83), 24 \%$ were in their fourth year $(n=33)$, and $17 \%$ were second year students $(n=24)$. All of them have completed courses in Syntax 3 and Morphology 2 which cover basic and important topics in the learning of grammar.

\subsection{Instruments}

Pajares and Miller (1995) cautioned that assessment of self-efficacy should be carefully designed to match particular task measured and must not be generalized. In this regard, two new instruments were developed in this study: A questionnaire, and a set of question for the measurement of grammar performance. The questionnaire consisted of two parts: Part A and Part B. In Part A, 18 items were designed to capture students efficacy in three different constructs: Correction of grammar errors (seven items), vocalization of words (six items), and construction of sentences (five items). These items covered all important topics in syntax and morphology. The participants were required to rate their level of perceived confidence in completing each of the items without attempting to answer them. All items were anchored on a 6-point Likert scale which ranged from $1=$ "strongly not confident" to $6=$ "strongly confident". Part B provided the demographic description of the respondents which included gender and year of study. The second instrument is a set of question with the same 18 items in the questionnaire. Participants were asked to explicitly write their answers for each of the items. Answers were then assessed by two lecturers in Arabic language.

Prior to data collection, all of the 18 items were reviewed by two academicians in the field of Arabic language from two public universities in Malaysia. The review is crucial to ensure that these items correspond to the underlying constructs, complying with the course contents and to suit the learners' linguistic level. They viewed that these items are fit to measure those constructs, but suggested a few amendments for clarity and readability.

\subsection{Procedure}

Data collection was conducted during regular class time after having consent from the lecturers concerned. Students were informed that completion of Syntax 3 and Morphology 2 is the criteria for selection. Their participation is voluntary and they are free to withdraw at any time. They were clearly told that they have to answer the questions in another booklet once they have finished rating their confidence level in the questionnaire. This is to ensure the full commitment and attention in rating the level of perceived efficacy. In general, participants took 20 minutes to complete the questionnaire and 1 hour to answer the questions. 


\subsection{Exploratory Factor Analysis}

Since the questionnaire used in this study is newly-developed to suit the objective, exploratory factor analysis is conducted to establish its psychometric properties. Preliminary analysis of the correlation matrix showed that all 18 items correlate fairly well and none of them are particularly large with most correlation values ranging from 0.313 to .746 . The value of the KMO Measure of Sampling Adequacy was .89 and Bartlett's test of sphericity was significant $(X 2(140)=1421, p<$ $.05)$. The results indicated that factorial analysis is appropriate for these data. Item communalities range between .53 to .79 , thus, conforming that each item shared some common variance with other factors.

The three-factor solution obtained from the principal component analysis with varimax rotation explained $63.48 \%$ of the total variance. Rotated component matrix revealed that the first factor consists of the first seven items representing a hypothesized subscale of correction of grammatical errors. It accounts for $43.44 \%$ of the variance. Cronbach Alpha for this factor is 0.87 . The second factor, which validates the hypothesized subscale of vocalization of words comprises of the next six items has the highest reliability index of .90 . It explains $11.89 \%$ of the variance. The final factor, contributes $8.16 \%$ of the variance has components of sentence construction with the last five items loaded on it. Cronbach Alpha for this factor is .84. Thus, all components were deemed reliable as the Cronbach alpha values exceeded the minimum threshold of 0.70 (Nunally, 1978).

Validation by principal component analysis has empirically demonstrated the ability of this new instrument in measuring self-efficacy in Arabic grammar in three major components: errors correction, words vocalization and sentence construction.

\section{Results}

\subsection{Students' Level of Grammar Efficacy}

An examination of the data from the questionnaire $(N=140)$ revealed that students efficacy in general is rather high $(M=4.61, S D=0.79)$, which indicates that students are almost confidence with their ability to answer the grammar questions. Table 1 shows that word vocalization efficacy appears to be the highest, $(M=4.96, S D=0.86)$, followed closely by efficacy on sentence construction $(M=4.76, S D=0.93)$, and finally error correction efficacy $(M=4.21, S D=1.02)$.

Table 1: Means of Overall Grammar Efficacy, Efficacy of Error Correction, Efficacy of Words Vocalization and Efficacy of Sentence Construction $(N=140)$

\begin{tabular}{lcc}
\hline & Mean & Standard Deviation \\
\hline Overall grammar efficacy & 4.61 & 0.79 \\
Efficacy of words vocalization & 4.96 & 0.86 \\
Efficacy of sentence construction & 4.76 & 0.93 \\
Efficacy of error correction & 4.21 & 1.02 \\
\hline
\end{tabular}

\subsection{Grammar Efficacy and Grammar Performance}

Pearson product-moment correlation coefficient $(r)$ was calculated to determine the strength and direction of relationship between grammar self-efficacy in the three components: error correction, word vocalization and sentence construction, with their achievement respectively (see Table 2). A moderate positive correlation is found between grammar efficacy and the overall grammar achievement $(r=.46, p<.05)$. This association indicates that, on the whole, the more efficacious students are in grammar, the better their grammar performance would be. However, a more detail examination revealed slightly weak correlations between the three components and their achievements, with sentence construction $(r=.38, p<.05)$ being the highest, followed by word vocalization $(r=.35, p<.05)$, and finally error correction $(r=.26, p<.05)$. Regardless of the slightly weak associations, these findings, however, support the second hypothesis of positive significant 
correlations between grammar efficacy on error correction, words vocalization and sentence construction with their grammar performance, respectively.

Table 2: Correlations between Overall Grammar Efficacy, Error Correction Efficacy, Word Vocalization Efficacy, Sentence Construction Efficacy, and Their Performance Respectively.

\begin{tabular}{|c|c|c|c|c|c|}
\hline & & $\begin{array}{c}\text { Error } \\
\text { correction } \\
\text { efficacy }\end{array}$ & $\begin{array}{l}\text { Word } \\
\text { vocalization } \\
\text { efficacy }\end{array}$ & $\begin{array}{l}\text { Sentence } \\
\text { construction } \\
\text { efficacy }\end{array}$ & $\begin{array}{l}\text { Overall } \\
\text { efficacy }\end{array}$ \\
\hline \multirow{3}{*}{$\begin{array}{l}\text { Achievement on error } \\
\text { correction }\end{array}$} & Pearson Correlation & $.255^{\prime \prime}$ & .377 & .400 & .397 \\
\hline & Sig. (2-tailed) & .002 & .000 & .000 & .000 \\
\hline & $\mathrm{N}$ & 140 & 140 & 140 & 140 \\
\hline \multirow{3}{*}{ Achievement on word vocalization } & Pearson Correlation & .226 & .348 & .346 & .354 \\
\hline & Sig. (2-tailed) & .007 & .000 & .000 & .000 \\
\hline & $\mathrm{N}$ & 140 & 140 & 140 & 140 \\
\hline \multirow{3}{*}{$\begin{array}{l}\text { Achievement on sentence } \\
\text { construction }\end{array}$} & Pearson Correlation & .225 & $.418^{\circ}$ & 380 & .390 \\
\hline & Sig. (2-tailed) & .007 & .000 & .000 & .000 \\
\hline & $\mathrm{N}$ & 140 & 140 & 140 & 140 \\
\hline \multirow{3}{*}{ Overall achievement } & Pearson Correlation & .284 & .459 & .454 & .459 \\
\hline & Sig. (2-tailed) & .001 & .000 & .000 & .000 \\
\hline & $\mathrm{N}$ & 140 & 140 & 140 & 140 \\
\hline
\end{tabular}

${ }^{* *}$. Correlation is significant at the 0.01 level (2-tailed).

\section{Discussion}

This study proved that learners of Arabic language are efficacious grammar learners, thus, supporting the findings of Collins and Bissell (2004) and Nik Hanan et al. (2013). They viewed themselves as having mastered sufficient grammar knowledge of morphology and syntax for the purpose of words vocalization, sentence construction and error correction. Among the three aspects, learners are much more confident in the vocalization of words in texts. This is particularly true in the context of Malaysia where reading skill is regarded as the most important skill in learning Arabic as compared to listening, speaking, and writing (Asmah, 1982). In addition, Arabic words are mostly left unvocalized in contemporary texts; a factor which automatically forces readers to vocalize them as they read. Hence, regardless of whether readers manage to achieve correct vocalization or not, this repeated exercise might largely contribute to enhance their perceived confidence in this aspect. With regard to sentence construction and error correction, these two aspects addressed the writing skill. Arabic learners tend to be more confidence in the former than the latter. This might be due to the fact that students have more freedom in constructing sentences by focusing on a particular grammatical rule, whereas in error correction, they have to carefully scrutiny the error by recalling unlimited types of grammatical rules

The moderate positive association between grammar efficacy and grammar performance differs slightly from the study by Collins and Bissell (2004) which revealed a weak association between grammar efficacy and grammar performance in learning English. As Arabic learners are more confident in judging their capabilities in words vocalization, sentence construction and error correction, their performance will simultaneously increase. Though efficacy level is the highest in words vocalization, association between sentence construction efficacy and its performance revealed the highest correlation. With high efficacy in sentence construction, learners tend to construct good sentences grammatically. This is an interesting finding for language learners, especially in grammar learning. After all, the ultimate goal of any language learning is the production of correct sentences verbally and written, both at the grammar and semantic levels.

\section{Conclusion}

In conclusion, the present study has proved the relevance of self-efficacy in Arabic language learning. By integrating this self-concept into the learning of grammar, teachers would be able to 
instill confidence among learners, thus improving their achievement in the core subject of Arabic language learning. In respond to the need for an appropriate assessment of self-efficacy, this study offers an established instrument for the purpose of measuring Arabic grammar efficacy. Accuracy has been established by focusing on three different tasks in grammar learning, which are words vocalization, sentence construction and error correction. However, more information about the impact of self-efficacy on grammar learning, as well as on other language skills, is necessary for future studies.

\section{References}

Asmah Haji Omar. (1982). Language and society in Malaysia. Kuala Lumpur: Dewan Bahasa dan Pustaka.

Bandura, A. (1986). Social foundations of thought and action: A social cognitive theory. Englewood Cliffs, NJ: Prentice Hall.

Collins, S. J. \& Bissell, K .L. (2002). Student self-efficacy in a media writing course. Journalism and Mass Communication Educator, 56(4), 19-36. doi:10.1177/107769580205600403.

Collins, S. J. \& Bissell, K .L. (2004). Confidence and competence among community college students: Selfefficacy and performance in grammar. Community College Journal of Research and Practices, 28, 663675. doi: 10.1080/10668920390254663.

Ghazali Yusri, Nik Mohd Rahimi, Parilah M. Shah, Wan Haslina Wah, \& Ahmed Thalal Hassan. (2011). Kepercayaan jangkaan keupayaan kendiri dalam kalangan pelajar kursus Bahasa Arab. GEMA Online ${ }^{T M}$ Journal of Language Studies, 11(1), 81-96. Retrieved from http://journalarticle.ukm.my/992/1/pp81_96.pdf

Krejcie, R. V. \& Morgan, D. W. (1970). Determining sample size for research activities. Educational and Psychological Measurement, 30, 607-610. doi: 10.1177/001316447003000308.

Linnenbrink, E. A. \& Pintrich, P. R. (2003). The Role of self-efficacy beliefs in student engagement and learning in the classroom. Reading \& Writing Quarterly, 19(2), 119-137. doi:10.1080/10573560308223.

Mills, N., Pajares, F., \& Herron, C. (2006). A Reevaluation of the role of anxiety: Self-efficacy, anxiety and their relation to reading and listening proficiency. Foreign Language Annals, 39, 276-295. doi: 10.1111/j.19449720.2006.tb02266.x

Mills, N., Pajares, F., \& Herron, C. (2007). Self-efficacy of college intermediate French students: Relation to achievement and motivation. Language Learning, 57(3), 417-442. doi: 10.1111/j.1467-9922.2007.00421.

Mohamad Azrien Mohamed Adnan \& Shukeri Mohamad. (2011). Language learning strategies and self-efficacy belief in Arabic language learning: A Malaysia context. ASEAN Journal of Teaching and Learning in Higher Education, 3(2), 48-59. Retrieved from http://journalarticle.ukm.my/2314/1/5_AJTLHE_78En_Mohahamad_Azrien_UM_KB.pdf

Nik Hanan Mustapha, Nik Farhan Mustapha, Nadwah Daud, \& Mahmud Abd Wahab. (2013). Arabic language efficacy questionnaire (ALEQ): Assessing self-efficacy and achievement. GEMA Online ${ }^{T M}$ Journal of Language Studies, 13(1), 155-167. Retrieved from http://journalarticle.ukm.my/6050/1/2232-4418-1-SM.pdf

Nunnally, J. C. (1978). Psychometric theory, 2nd edition. New York, NY: McGraw-Hill.

Pajares, F. (1996). Self-efficacy beliefs in academic settings. Review of Educational Research, 66(4), 543-578. doi: 10.3102/00346543066004543.

Pajares, F. (2003). Self-efficacy beliefs, motivation and achievement in writing: A review of the literature. Reading \& Writing Quarterly, 19, 139-158. doi: 10.1080/10573560390143085.

Pajares, F. \& Johnson, M. D. (1994). Confidence and competence in writing: The role of self-efficacy, outcome expectancy, and apprehension. Research in the Teaching of English, 28(3), 313-331. doi: $10.1080 / 10573560308222$.

Pajares, F. \& Miller, M. D. (1995). Mathematics self-efficacy and mathematics performances: The need for specificity of assessment. Journal of Counseling Psychology, 42(2), 190-198. doi: 10.1037/00220167.42.2.190.

Schunk, D. H. (2003). Self-efficacy for reading and writing: Influence of modeling, goal setting and selfevaluation. Reading \& Writing Quarterly, 19, 159-172. doi: 10.1080/10573560308219.

Schunk, D. H. \& Zimmerman, B. J. (2007). Influencing children's self-efficacy and self-regulation of reading and writing through modeling. Reading \& Writing Quarterly, 23, 7-25. doi: 10.1080/10573560600837578.

Shell, D. F., Colvin, C., \& Bruning, R. H. (1995). Self-efficacy, attribution and outcome expectancy mechanisms in reading and writing achievement: Grade-level and achievement-level differences. Journal of Educational Psychology, 87(3), 386-398. doi: 10.1037/0022-0663.87.3.386.

Zimmerman, B. J. (1996). Measuring and mismeasuring academic self-efficacy: Dimensions, problems, and misconceptions. Paper presented at the Annual Meeting of the American Educational Research Association, New York. 